\title{
Capital-Intensive Projects Induce More Effort Than Labor-Intensive Projects
}

\author{
Amihai Glazer \\ Department of Economics \\ University of California, Irvine \\ Irvine, California 92697 \\ USA \\ Stef Proost \\ Center for Economics Studies \\ Katholieke Universiteit Leuven \\ Naamsestraat 69 \\ B-3000 Leuven \\ Belgium
}

December 12, 2008

\begin{abstract}
Central governments often subsidize capital spending by local governments, instead of subsidizing operating expenses or labor-intensive projects. This paper offers one explanation, focusing on the incentive effects for local officials - a local official can more easily shift the cost of optimizing a project to his successor on a labor-intensive project than on a capital-intensive project.
\end{abstract}

Keywords: federalism, capital subsidies, transit subsidies

JEL codes: H77, H71, L92 


\section{Introduction}

Central governments often subsidize the capital costs of local projects but not the operating costs. In transportation, for example, the federal government subsidizes construction of roads, but not their maintenance; and it subsidizes the purchase of buses but not operating costs. Why? One argument is the concern with commitment and with durability. But it is not obvious that the federal government would have a greater incentive to build durable projects than would a local government.

Relatedly, voters who currently influence the central government may fear losing future influence. So though the central government may promise an operating subsidy, the local citizens may fear that the central government's preferences will change, canceling the subsidy or imposing stricter conditions on it. The local voters may therefore prefer a capital-intensive project.

In some countries, local governments have only a limited tax base, making it difficult for them to adopt capital-intensive projects; the central government may then want to subsidize such projects. In other countries the opposite may hold. For example, in the United States local governments can issue tax-free bonds at low interest rates.

This paper takes a different approach, looking at the incentives of a local official, say the mayor, to exert effort. We shall show that a mayor may work harder if he is responsible for a capital-intensive project than if he is responsible for a labor-intensive project. For on a project having low capital intensity, a free-rider problem can appear. The mayor in each period may want to leave to a future mayor the task of optimizing the project. In contrast, a capital project can be optimized only when it is adopted, and so the mayor in office when the project is adopted may be induced to exert effort in optimizing a capital-intensive project.

We first review other possible explanations for a bias toward capital-intensive projects. We next present the assumptions and use a simple model to illustrate the bias in the management of different projects. We conclude with a discussion of capital subsidies as a remedy.

\section{Literature}

\subsection{Inefficient policies}

Several political factors can explain the adoption of inefficient policies. (1) When the policy makes transfers to special interests, the efficient direct transfers may be politically costly. In contrast, transfers resulting from a program that is not ostensibly aimed at redistribution may fool the public, and so may face weak opposition. Tullock (1983) terms such programs "disguised" transfers. Coate and Morris (1995) formalize the argument, seeing cash as a direct transfer, whereas a public project may be undertaken either because the incumbent aims to make a transfer to some group, or because the incumbent believes the project has 
social benefits. Cash transfers reveal that the politician is of a type who caters to special interests; for public projects the politician's type remains uncertain.

(2) Inefficient policies may commit future governments. Glazer (1989) shows that a current government unsure about a future government's support for a program will favor durable projects. Attempts to shape future preferences can lead to similar results. Acemoglu and Robinson (2001) argue that the current majority may favor policies that increase its size, or increase its future political power, even if those policies are inefficient when viewed as affecting only current incomes.

(3) Politicians can reduce future spending by committing to inefficient policies; for example if spending is affected by pressure group politics, then taxes which cause much deadweight loss will result in low spending (see Rodrik 1986, Wilson 1990, and Becker and Mulligan 1998).

(4) Relatedly, a government may increase its bargaining power over a special interest by constraining itself to inefficient programs that reduce the benefit a special interest could obtain (see Drazen and Limao 2003).

\subsection{Delay}

Other work examines how uncertainty can induce delay. Applying the standard analysis of option value shows the conditions under which an executive who expects to get more information soon should postpone any irreversible, costly, action. $^{1}$

\subsection{Time horizon of public officials}

Other work relates to our assumption that a leader cares about outcomes after he yields power, and may take actions now to affect future outcomes. Glazer and Kannianen (2007) consider a public official's incentive to incur the cost of searching for a good subordinate when the official can shift that cost to his successor.

\subsection{Financial capacity}

In some countries, the tax base of local governments is small, making it difficult for them to finance capital-intensive projects, and so inducing the central government to subsidize capital. But conditions vary by country. In the U.S., local governments can issue bonds with only a small interest cost differential. Alternatively, the federal government can give a state guarantee and then capital subsidies are not necessary.

\footnotetext{
${ }^{1}$ See Arrow and Fisher 1974, Pindyck 1991, and Dixit 1992.
} 


\section{Assumptions}

We make two central assumptions. First, the incumbent political leader (we will call him the mayor) benefits from the project after he leaves office. He may care because he continues to live in the city he governed, affected by decisions like other residents are. Or perhaps the incumbent cares about future performance because he owns real property, with an optimized project generating better public services and therefore higher property values. ${ }^{2}$ Of course, often externalities (negative or positive spillovers) to other jurisdictions appear. Such externalities can justify a central government's concern with local performance. But since the externalities can hold whatever the project's capital intensity, we ignore them here.

A second assumption is that a capital-intensive project can be optimized only when it is adopted, whereas a labor-intensive project can be optimized in any period. Take the example of urban transit, where a light-rail project requires fixing the routes for the tracks before the project is even completed, whereas the less capital-intensive bus routes can be changed any time. This asymmetry in timing means that a mayor cannot impose on a later mayor the cost of optimizing a capital-intensive project. But a mayor who does not optimize a labor-intensive project may expect a later mayor to incur the cost of optimizing the project.

We compare the behavior of a mayor when faced with two types of projects. One is a capital-intensive project, which can be optimized only when the project is adopted. A labor-intensive project has no design of capital. But its operation can be optimized in any period; optimizing a project in one period generates efficient operation in all future periods, and allows for no further improvement.

An optimized project (whether capital-intensive or labor-intensive) yields benefit $V_{H}$ in each period; a non-optimized project (whether capital-intensive or labor-intensive) yields benefit $V_{L}$, with $v_{H}>v_{L}$. We normalize the benefits, with $v_{L}=0$. A mayor who optimizes a project bears a cost $F$. A mayor discounts future benefits by the discount rate $r$.

\section{Free-riding in optimizing a project}

\subsection{Capital-intensive project}

Consider first a capital-intensive project, which can be optimized only by the mayor when the project was adopted. The benefits when he works on optimizing are

$$
-F+\sum_{t=0}^{\infty} \frac{v_{H}}{(1+r)^{t}}=\frac{v_{H(1+r)}}{r}-F .
$$

\footnotetext{
${ }^{2}$ Relatedly, Alesina and Tabellini (2004) argue that when a bureaucrat's utility increases with his perceived competence, career concerns can motivate bureaucrats.
} 
A current mayor who does not optimize has 0 benefits. So the mayor optimizes if

$$
F<\frac{1+r}{r}\left(v_{H}\right) .
$$

\subsection{Labor-intensive project}

Consider next optimizing a labor-intensive project. As before, a mayor who optimizes a project has expected discounted benefits of $\frac{v_{H(1+r)}}{r}-F$, the same as with optimizing a capital-intensive project.

Recall that a mayor who does not optimize a project benefits from optimization made by a successor, but saves the cost of the effort $F$, as this is individualized effort, not outsourced project preparation. Then a current mayor who does not optimize the project whereas his successor does enjoys benefits

$$
\sum_{t=1}^{\infty} \frac{v_{H}}{(1+r)^{t}}=v_{H} / r
$$

The mayor therefore optimizes the project if $F<v_{H}$. Notice that this condition is more stringent than the condition for optimizing a capital-intensive project, which was $F<\frac{1+r}{r}\left(v_{H}\right)$. The interesting case has the inequality $F<v_{H}$ violated, so that no Nash equilibrium has a pure strategy, in which the mayor in any period optimizes a labor-intensive project with probability 1 .

The Nash equilibrium will instead have mixed strategies. ${ }^{3}$ Let the probability that any one future mayor optimizes the project be $s$. If the current mayor does not optimize the project, then with probability $s$ his successor in the next period will; with probability $(1-s) s$ his successor in two periods will, and so on. The current mayor's expected benefits when he does not optimize the project are thus

$$
\sum_{t=1}^{\infty}\left((1-s)^{t-1} s \sum_{i=t}^{\infty} \frac{v_{H}}{(1+r)^{i}}\right)=\frac{s v_{H}(1+r)}{r(r+s)} .
$$

In an equilibrium with mixed strategies, a mayor is indifferent between optimizing the project or not, so that

$$
\frac{v_{H(1+r)}}{r}-F=\frac{s v_{H}(1+r)}{r(r+s)}
$$

Solving for $s$ yields

$$
s=\frac{\left(r\left(v_{H}-F\right)+v_{H}\right)}{F} .
$$

We must check that this value of $s$ lies in $[0,1]$ when $F<\frac{1+r}{r}\left(v_{H}\right)$, that is, when the mayor would not optimize the project. Using (6) we find indeed

\footnotetext{
${ }^{3}$ Though we discuss mixed strategies, similar results can appear with correlated equilibria. For example, $s$ could be the probability that the next mayor will be a Democrat, and the equilibrium could have a Democrat optimize a labor-intensive project, whereas a Republican would not.
} 


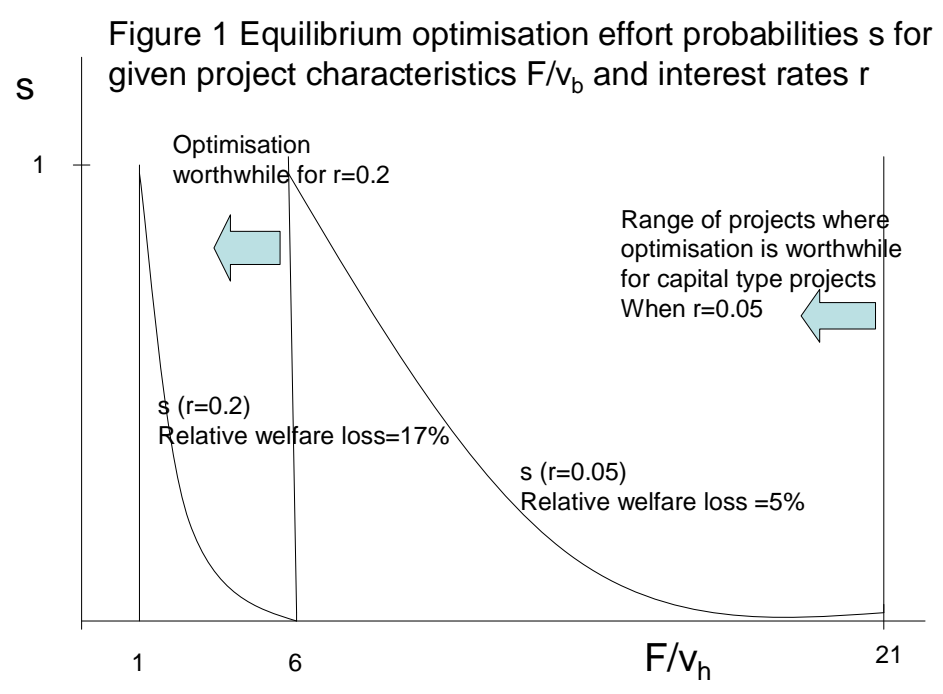

that $s=0$ for $\frac{F}{v_{H}}=\frac{1+r}{r}$. The incumbent would optimize neither a capitalintensive nor a labor-intensive project. We will find that $s=1$ for $\frac{F}{v_{H}}=1$. This means that for a whole range of projects with $1<\frac{F}{v_{H}}<\frac{1+r}{r}$ a mayor is indifferent between a labor-intensive project and a capital-intensive project. In each of these problems, the mayor optimizes a labor-intensive project only with probability $s<1$. If, instead, the mayor had a capital-intensive project, he would have optimized it.

We illustrate in Figure 1 the probability $s$ that a mayor optimizes a laborintensive project that had not already been optimized. The figure is limited to values of $\frac{F}{v_{H}}$ within the range $1<\frac{F}{v_{H}}<\frac{1+r}{r}$; it considers two discount rates (5\% and 20\%). At a low discount rate, up to $\left.\frac{F}{v_{H}}=\frac{1+r}{r}=21\right)$, the mayor would optimize a labor-intensive-project. For high values of $\frac{F}{v_{H}}$, we see that the probability $s$ decreases. In the whole range of $\frac{F}{v_{H}}$ values considered. Recall that a value of $s<1$ means that a mayor may not optimize a labor-intensive project, resulting in inefficiency.

Consider next a higher discount rate for the mayor (20\%). We see that the mayor would optimize a capital-intensive project if $\left(\frac{F}{v_{H}}=\frac{1+r}{r} \leq 6\right)$. For projects with $\frac{F}{v_{H}} \leq 6$, the value of $s$ increases slowly.

\subsection{Welfare cost of low effort}

How important is the lack of optimizing a labor-intensive project? In the range of projects with $1<\frac{F}{v_{H}}<\frac{1+r}{r}$, the mayor enjoys the same utility under a capital-intensive project he optimizes as under a labor-intensive project he does 
not. But because the mayor does not consider the effort $F$ shifted onto his successors, a mayor's utility can differ from social welfare.

Welfare under a capital-intensive project is $\frac{v_{H(1+r)}}{r}-F$. Welfare under a labor-intensive project optimized by a mayor with probability $s$ (considering the effort of the mayor and his successors) is

$$
\frac{s}{r+s} \frac{(1+r) v_{H}}{r}-s F \frac{1}{r+s}
$$

The welfare loss $L$ under a labor-intensive project compared to a capitalintensive project is

$$
L=\frac{r}{r+s},
$$

so that for small values of $s$ the efficiency loss approaches $100 \%$. This makes sense, as low values of $s$ mean that any mayor is unlikely to optimize a laborintensive project, though such optimization increases aggregate welfare. But $s$ itself declines with $r$ (see Figure 1), so after substitution by the equilibrium value of $s(6)$, we obtain the welfare loss as a function of the discount rate $r$. So in our example of Figure 1, the welfare loss is approximately $5 \%$ for $r=5 \%$, and $17 \%$ for $r=20 \%$.

The intuition is that higher discount rates reduce the probability of optimizing a labor-intensive project. For a capital-intensive project, the future benefits of optimizing it also decrease. But, in the range of values considered, the mayor always optimizes a capital-intensive project. In contrast, the probability of optimizing a labor-intensive project declines with the discount rate, and so the welfare loss rises with the discount rate.

Of course, the absolute welfare loss $A L$ is a function of the net benefit of optimizing a project. This absolute loss declines with $\frac{F}{v_{H}}$ and with the discount rate:

$$
A L=\frac{r}{r+1}\left(\frac{1+r}{r}-\frac{F}{v_{H}}\right) v_{H}=\left(1-\frac{r}{1+r} \frac{F}{v_{H}}\right) v_{H} .
$$

So higher discount rates reduce what is at stake when the mayor optimizes a project, absolute losses decline but relative losses increase. The value $\frac{F}{v_{H}}$ is the relative cost of optimizing a project compared to the benefits, and so a high cost of optimizing a project makes low probabilities of optimizing result in a small loss of welfare.

If the mayor uses a different discount rate $r$ from the social discount rate $(i)$, the expressions for absolute and relative welfare loss change. If the parameters continue to be such that it is socially optimal to optimize a project the loss is

$$
L(r, i)=\frac{i}{i+s}=\frac{i}{i+s(r, i)}=\frac{i F}{1+i F-r\left(\frac{F}{v_{H}}-1\right)}
$$

This loss increases with the discount rate used by the mayor. A mayor with a short time horizon will not optimize a labor-intensive project, generating a high efficiency loss. 


\subsection{Corrective policies}

How to correct the welfare loss under labor-intensive projects? We can think of regulatory, institutional, and incentive policies. In assessing policies we should consider the limited information that the central government may have about local conditions, and to consider possible distortions that these policies generate.

A starting point may be for the central government to forbid, or to refuse to fund, labor-intensive projects when a capital-intensive project offers the same services at the same cost of optimizing a project. Such a blunt policy would, however, reduce opportunities for creativity at the local level. A more intelligent federal oversight may be to rely on yardstick competition, so that the choice of inefficient labor-intensive projects could be detected. But this type of oversight may be difficult in a mixed-strategy equilibrium: one may sometimes observe serious optimization efforts and sometimes not at all. Large variation in the quality of a labor-intensive project remains a good signal to detect the inefficiency we describe.

A more institutional approach would extend the term limits of the politicians. An extension of the term limit implies that a mayor will see higher rewards for optimizing a labor-intensive project. Extending term limits has obvious drawbacks when the politician in office is inefficient or pursues other goals.

A more straightforward, approach is to subsidize a capital-intensive project. But such a subsidy also has drawbacks. The subsidies may induce a local government to adopt too many projects, and to favor capital-intensive projects when labor-intensive projects would be more efficient.

A fourth type of policy would be to reduce the costs of effort for the local policy maker. But as these are individualized and can consist of political opportunity costs, this is difficult to operationalize.

\section{Conclusion}

This paper claimed that capital-intensive projects induce greater effort by public officials than do labor-intensive projects. It is difficult to observe effort, and even more difficult to test the hypothesis. Yet some evidence supports the hypothesis.

Obeng and Sakano (2000) contrast how total factor productivity in the public transit industry responds to operating subsidies and to capital subsidies. Our model would predict that local officials put more effort into using capital efficiently than into improving ongoing operations, and therefore that capital subsidies enhance productivity growth more than do operating subsidies. The authors find that.

When the effects we discuss apply, voters will favor capital subsidies over operating subsidies. That is the common pattern in the United States. Of course, some operating policies have little political appeal; we rarely see a politician celebrating the good maintenance of an old sewer line. But neither do politicians seek publicity over the construction of a new, technologically sophisticated, 
sewer. So we must ask why voters may prefer that the federal government subsidize building but not maintaining sewer lines; the model presented above gives one answer.

The bias by the U.S. federal government toward subsidizing construction, but providing no assistance for maintenance or other operating expense, is well documented by Cromwell (1989). For example, in 1988 the federal government provided grants to states to complete, rehabilitate, and reconstruct the interstate highway system at a 90 percent matching rate. Discretionary grants from the Urban Mass Transit Administration (UMTA) subsidized construction of major rail and subway systems with up to a 75 percent matching rate. Formula grants from UMTA paid 80 percent of the cost of regular transit vehicle replacement. No corresponding subsidies, however, are provided for maintenance. This pattern is confirmed by Taylor and Kelly (2002) in their discussion of Federal public transit policy.

The bias toward capital-intensive projects will vary with conditions. For example, term limits will increase the bias - an incumbent who does not address maintenance problems or inefficient operations knows that his successor may. Though we have no data to test for this effect, our approach offers a prediction opposite to most models of term limits, namely that short terms of office lead politicians to focus on short-term problems, rather than on how best to implement a new construction project. The length of the time horizon can affect not only the level of effort by a public official, but also the distribution of effort. 


\section{Notation}

$F$ Cost of optimizing a project

$v_{H}$ Benefit from project in each period from an optimized project

$r$ Intertemporal discount rate

i Intertemporal discount rate of the mayor if it differs from $r$

$s$ Probability an official optimizes a project if his predecessor had not 


\section{References}

[1] Acemoglu, Daron and James Robinson (2001) "Inefficient redistribution." American Political Science Review, 95: 649-661.

[2] Alesina, Alberto and Guido Tabellini (2004) "Bureaucrats or politicians?" National Bureau of Economic Research, Working Paper No. 10241.

[3] Arrow, Kenneth and Anthony C. Fisher (1974) "Preservation, uncertainty, and irreversibility." Quarterly Journal of Economics, 88: 312-319.

[4] Becker, G. and C. Mulligan (1998) "Deadweight costs and the size of government." National Bureau of Economic Research, Working Paper No. 6789.

[5] Coate, Stephen and Stephen Morris (1995) "On the form of transfers to special interests." Journal of Political Economy, 103: 1210-1235.

[6] Cromwell, Brian A. (1989) "Capital subsidies and the infrastructure crisis: Evidence from the local mass-transit industry." Federal Reserve Bank of Cleveland Economic Review, 25(2): 11-21.

[7] Dixit, Avinash (1992) "Investment and hysteresis." Journal of Economic Perspectives, 6(1): 107-132.

[8] Drazen, Allan and Nuno Limao (2003) "Government gains from selfrestraint: A bargaining theory of inefficient redistribution policies." (August 2003). CEPR Discussion Paper No. 4007

[9] Glazer, Amihai (1989) "Politics and the choice of durability." American Economic Review, 79(5): 1207-1213.

[10] Glazer, Amihai and Vesa Kanniainen (2007) "Short-term leaders should make long-term appointments." International Tax and Public Finance, 14(1): 55-69.

[11] Taylor, Brian D. and Kelly Samples (2002) "Jobs, jobs, jobs: Political perceptions, economic reality, and capital bias in U.S. transit subsidy policy." Public Works Management Policy, 6(4): 250-263.

[12] Obeng, Kofi and Ryoichi Sakano (2000) "The effects of operating and capital subsidies on total factor productivity: A decomposition approach." Southern Economic Journal, 67(2): 381-397.

[13] Pindyck, Robert S. (1991) "Irreversibility, uncertainty, and investment." Journal of Economic Literature, 29: 1110-1148.

[14] Rodrik, Dani (1986) "Taxes, subsidies, and welfare with endogenous policy." Journal of International Economics, 21: 285-299. 
[15] Tullock, Gordon (1983) Economics of Income Redistribution, Boston MA: Kluwer-Nijhoff.

[16] Wilson, Jay (1990) "Are efficiency improvements in government transfer policies self-defeating in political equilibrium." Economics and Politics, 2: 241-258. 